\title{
Prognostic impact of paraneoplastic syndromes on patients with non-metastatic renal cell carcinoma undergoing surgery: Results from Canadian Kidney Cancer information system
}

Ryan Sun ${ }^{1}$; Rodney H. Breau ${ }^{2}$; Ranjeeta Mallick ${ }^{2}$; Simon Tanguay ${ }^{3}$; Frederic Pouliot ${ }^{4}$; Anil Kapoor$^{5}$; Luke T. Lavallée ${ }^{2}$; Antonio Finelli ${ }^{6}$; Alan I. So ${ }^{7}$; Ricardo A. Rendon ${ }^{8}$; Adrian S. Fairey ${ }^{9}$; Jean-Baptiste Lattouf ${ }^{10}$; Jun Kawakami ${ }^{11}$; Bimal Bhindi ${ }^{11}$; Naveen S. Basappa ${ }^{12}$; Lori A. Wood $^{8}$; Georg A. Bjarnason ${ }^{13}$; Daniel Y. C. Heng ${ }^{14}$; Rahul Bansal ${ }^{1}$

${ }^{1}$ Department of Surgery, University of Manitoba, Winnipeg, MN, Canada; ${ }^{2}$ Division of Urology, University of Ottawa, Ottawa, ON, Canada; ${ }^{3}$ Division of Urology, McGill University, Montreal, QC, Canada; ${ }^{4}$ Division of Urology, Department of Surgery, Université Laval, Quebec City, QC, Canada; ${ }^{5}$ Division of Urology, McMaster Institute of Urology, Hamilton, ON, Canada; ${ }^{6}$ Division of Urology, University of Toronto, Toronto, ON, Canada; ${ }^{7}$ Department of Urologic Sciences, The University of British Columbia, Vancouver, BC, Canada; ${ }^{8}$ Department of Medicine and Urology, Dalhousie University, Halifax, NS, Canada; ${ }^{9}$ Division of Urology, University of Alberta, Edmonton, AB, Canada; ${ }^{10}$ Department of Surgery, Université de Montréal, Montreal, QC, Canada; ${ }^{11}$ Southern Alberta Institute of Urology, Calgary, AB, Canada; ${ }^{12}$ Department of Oncology, University of Alberta, Edmonton, AB, Canada; ${ }^{13}$ Division of Medical Oncology/Hematology, Sunnybrook Odette Cancer Centre, University of Toronto, Toronto, ON, Canada; ${ }^{14}$ Tom Baker Cancer Centre, University of Calgary, Calgary, AB, Canada

Acknowledgment: This study was supported by the Kidney Cancer Research Network of Canada.

Cite as: Sun R, Breau RH, Mallick R, et al. Prognostic impact of paraneoplastic syndromes on patients with non-metastatic renal cell carcinoma undergoing surgery: Results from Canadian Kidney Cancer information system. Can Urol Assoc J 2020 September 28; Epub ahead of print. http://dx.doi.org/10.5489/cuaj.6833

Published online September 28, 2020

$* * *$

\section{Abstract}

Introduction: The impact of paraneoplastic syndromes (PNS) on survival in patients with renal cell carcinoma (RCC) is uncertain. This study was conducted to analyze the association of PNS with recurrence and survival of patients with non-metastatic RCC undergoing nephrectomy. Methods: The Canadian Kidney Cancer information system is a multi-institutional cohort of patients started in January 2011. Patients with nephrectomy for non-metastatic RCC were identified. PNS included anemia, polycythemia, hypercalcemia, and weight loss. Associations between PNS and recurrence or death were assessed using Kaplan-Meier curves and multivariable analysis. 
Results: Of 4337 patients, 1314 (30.3\%) had evidence of one or more PNS. Patients with PNS, were older, had higher comorbidity, and had more advanced clinical and pathological tumor characteristics as compared to patients without PNS (all $\mathrm{p}<0.05)$. Kaplan-Meier five-year estimated recurrence-free survival (RFS), cancer-specific survival (CSS), and overall survival (OS) were significantly worse in patients with PNS $(63.7 \%, 84.3 \%$, and $79.6 \%$, respectively for patients with PNS vs. $73.9 \%, 90.8 \%$, and $90.1 \%$, respectively for patients without PNS, all $\mathrm{p}<0.005$ ). On univariable analysis, presence of PNS increased risk of recurrence (hazard ratio [HR] 1.67, 95\% confidence interval [CI] 1.48-1.90, $<<0.0001$ ) and cancer-related death (HR $1.85,95 \%$ CI 1.34-2.54, $\mathrm{p}=0.0002)$. Adjusting for known prognostic factors, PNS was not associated with recurrence or survival.

Conclusions: In non-metastatic RCC patients undergoing surgery, presence of PNS is associated with older age, higher Charlson comorbidity index score, advanced tumor stage, and aggressive tumor histology. Following surgery, baseline PNS is not strongly independently associated with recurrence or death.

\section{Introduction}

Paraneoplastic syndromes (PNS) are a collection of clinical signs and symptoms in cancer patients as a result of systemic effects from the tumor, unrelated to metastasis, infection, or treatment ${ }^{1}$. This phenomenon has been postulated to arise from aberrant hormonal regulations related to mediator proteins produced by the underlying neoplasm, but the exact molecular mechanism remains unknown ${ }^{1}$. Renal cell carcinoma (RCC) is well known to be associated with PNS, with an estimated $10 \%$ to $40 \%$ of RCC patients developing paraneoplastic manifestations ${ }^{1,2}$. The associated PNS are wide ranged, including hematologic (anemia ${ }^{3}$, polycythemia $^{4}$ ), metabolic (hypercalcemia ${ }^{5}$, hyperglycemia ${ }^{6}$ ), hepatic (Stauffer's syndrome ${ }^{7}$ ), and constitutional (fever, weight $\operatorname{loss}^{8}$ ).

On average, symptomatic patients have more advanced disease and worse survival compared to those with RCC who are asymptomatic ${ }^{8,9}$. Recent studies have found that abnormal laboratory values, in otherwise asymptomatic patients, such as hypercalcemia and anemia were associated with worse survival outcomes after nephrectomy ${ }^{10}$. However, the prognostic impact of PNS in patients with RCC is uncertain; the incidence or severity of PNS has not consistently correlated with tumor size, pathology, and metastasis ${ }^{11}$. Therefore, PNS are not always linked to poor prognosis and it remains unknown whether their presence in patients with localized disease have significant prognostic implications. In this study, we aimed to determine if pre-surgical PNS were associated with risk of cancer recurrence and survival for patients with non-metastatic RCC. 


\section{Methods}

\section{Patient selection}

The Canadian Kidney Cancer information system (CKCis) is a prospective cohort of RCC patients from 16 academic sites in six provinces. Patients who underwent radical or partial nephrectomy for non-metastatic RCC from January 2011 to December 2019 were identified and included. All participating institutions received appropriate institution specific REB approval.

\section{Data collection}

Baseline and clinical parameters included age, sex, race, family history, smoking history, Charlson Co-morbidity Index (CCI), and pre-operative clinical stage. For calculation of CCI, current diagnosis of kidney cancer was not included. The postoperative pathological parameters studied included histological subtype, pathological grade, presence of necrosis, sarcomatoid differentiation, stage, surgical margin, and lymph node metastases. To assess for PNS, preoperative symptoms and laboratory measurements were assessed. In this study, PNS included anemia $(\mathrm{Hb}<125 \mathrm{~g} / \mathrm{L}$ for male, $\mathrm{Hb}<115 \mathrm{~g} / \mathrm{L}$ for female), polycythemia $(\mathrm{Hb}>170 \mathrm{~g} / \mathrm{L}$ for male, $\mathrm{Hb}>155 \mathrm{~g} / \mathrm{L}$ for female), hypercalcemia (serum calcium $>2.7 \mathrm{mmol} / \mathrm{L}$ ), and weight loss (any of abnormal weight loss, excessive weight loss, unexplained weight loss, or recent weight loss recorded as described by the patient). Patients with benign histology or metastases were excluded. Following surgical recovery, patients without metastases were updated annually. Those that developed metastases were updated every 3 months until death.

\section{Statistical analysis}

Clinical and pathologic features between patients with and without PNS were summarized using means and proportions. Statistical comparisons in baseline factors were performed using t-tests or chi-square tests. Patient outcomes included recurrence, cancer specific death, and death from any cause. Time to these outcomes were estimated using the Kaplan-Meier method ${ }^{12}$. Survival intervals were defined as the time from nephrectomy to time of recurrence (recurrence free survival), time of death related to RCC (cancer specific survival), and time of death related to any cause (overall survival). The log-rank tests were used for univariable analyses and the Cox proportional hazards models were used to adjust for potential confounders. A-priori, models for cancer outcomes were adjusted for by known prognostic factors (tumor size, tumor grade, margin status). Overall survival was also adjusted for baseline comorbidity. The comparisons were summarized with hazard ratios (HRs) and 95\% confidence intervals (CIs). All tests were two-sided and $\mathrm{p}$ values of $5 \%$ or less were considered statistically significant. No adjustment was made for multiple testing. 


\section{Results}

Out of 4337 patients, 1314 (30.3\%) had evidence of one or more PNS. The most common PNS in this cohort was anemia (90.0\%), followed by weight loss $(11.8 \%)$, polycythemia $(3.6 \%)$, and hypercalcemia (1.1\%). Clinical and pathological features are summarized in Table 1. There was no significant difference in sex, race, family history of kidney cancer, or smoking history between those with and without PNS. Median follow up was similar in both groups. Patients with PNS were older, had higher Charlson comorbidity score, more advanced clinical and pathological tumor stage, higher tumor grade, advanced clinical and pathological lymph nodal involvement, positive tumor margin and presence of tumor necrosis and sarcomatoid differentiation as compared to those without PNS. PNS were present more frequently in patients with clear cell RCC as compared to papillary and chromophobe RCC ( $\mathrm{p}=0.009)$.

Anemia alone was present more frequently in patients with older age, higher CCI score (both $\mathrm{p}<0.0001)$, advanced clinical and pathological T stage $(\mathrm{p}<0.0001)$, advanced clinical $(p<0.0001)$ and pathological lymph nodal stage $(p=0.009)$, higher tumor grade $(p<0.0001)$, positive tumor margin $(\mathrm{p}=0.0002)$ and clear cell RCC $(\mathrm{p}=0.016)$. Weight loss was associated with older age $(p=0.02)$, advanced clinical and pathological $T$ stage $(p<0.0001)$, higher tumor grade $(\mathrm{p}<0.0001)$, and advanced clinical $(\mathrm{p}<0.0001)$ and pathological lymph nodal stage $(\mathrm{p}=0.03)$.

Kaplan-Meier estimated survival curves are shown in Figure 1. Five-year estimated RFS, CSS, and OS were significantly worse in patients with PNS (63.7\% [95\% CI 59.7, 67.5], 84.3\% [95\% CI 80.7, 87.2] and 79.6\% [95\% CI 75.8, 82.9] respectively for patients with PNS vs. 73.9\% [95\% CI 71.2, 76.4], 90.8\% [95\% CI 88.8, 92.5] and 90.1\% [95\% CI 88.1, 91.8] respectively for patients without PNS, all $\mathrm{p}<0.005$ ).

Associations of clinical and pathological parameters with RFS, CSS and OS are summarized in Table 2. During study period, 720 patients had evidence of tumor recurrence. Out of 286 patients that died during study period, 48 patients did not have known cause of death and were excluded from CSS analysis. Older age at nephrectomy, higher CCI score, tumor size, grade and stage were all significant predictors of worse RFS, CSS and OS (all $\mathrm{p}<0.05$ ) on univariable and multivariable analysis. Positive tumor margin was associated with poor RFS $(p<0.0001)$, CSS $(p=0.0002)$ and OS $(p<0.0001)$ on univariable analysis but only predicted poor RFS on multivariable analysis $(\mathrm{p}=0.003)$. On univariable analysis, presence of PNS adversely affected RFS (HR 1.67, 95\% CI 1.48-1.90, $\mathrm{p}<0.0001$ ) and CSS (HR 1.85, 95\% CI 1.34-2.54, $\mathrm{p}=0.0002$ ) [Table 1]. When adjusted for age, CCI score, tumor size, grade, pathological stage, tumor margin and histological subtype on the multivariable analysis, PNS only trended towards worse RFS, and CSS. Presence of PNS did not affect OS on univariable or multivariable analysis. 


\section{Discussion}

In this cohort study, one or more PNS were present in about $30 \%$ of patients. This is consistent with other studies that suggest PNS is prevalent in upto $40 \%$ of RCC patients ${ }^{1,2}$. On average, patients with PNS had more advanced and aggressive cancer. While patients with PNS have worse prognosis compared to those without PNS, this difference seems to be explained by other known prognostic factors.

Implications of PNS for those presenting with localized RCC remains unclear. Few studies have evaluated the effect of PNS on oncological outcomes after nephrectomy. Some studies found that pre-operative cachexia and weight loss were associated with more advanced tumors $^{3,13}$, and more recently, a study by Moreira et al found that those with PNS undergoing nephrectomy had significantly worse cancer specific and disease free survival owing to adverse pathologic features ${ }^{14}$. Similar to other studies, we found that patients with pre-operative PNS were more likely to have advanced tumor stage and grade $(p<0.0001)$ compared to those without. In addition, we further report significant associations of PNS with older age, higher CCI score, clinical and pathological nodal involvement, positive margins, presence of tumor necrosis and sarcomatoid differentiation on histology, all of which may further explain the markedly worse survival for those with PNS. Indeed, our univariate analysis showed that PNS was predictive of significantly worse RFS and CSS $(p<0.0001)$ over a median follow-up of around 2 years. However, when adjusted for age, CCI, tumor size, grade, stage, margin status and histological subtype, PNS did not predict worse survival outcomes. Therefore, the presence of PNS may be predictive of more advanced and aggressive tumors along with unfavorable baseline patient characteristics, which in turn lead to worse postoperative survival outcomes. In other words, these results suggest that PNS may be a reflection of the underlying ability of the tumor to behave aberrantly against the patient's innate defense, rather than a direct cause of morbidity and mortality.

RCC is commonly diagnosed incidentally through abdominal imaging performed for investigation of non-specific abdominal complaints or surveillance of other conditions. Those symptomatic at presentation, including hematuria, mass effect, and flank pain, are known to have worse tumor characteristics and survival outcomes. For example, they were found to have higher likelihood of high tumor grade, stage ${ }^{8}$, and metastatic spread ${ }^{3}$, which account for an observable survival difference between those with incidental and symptomatic disease.

Based on the literature, the most commonly reported PNS is anemia with a prevalence range of $20-40 \%{ }^{1,14}$. In our study, anemia was similarly found to be the most prevalent PNS, accounting for $27 \%$ of all patients and present in $90 \%$ of the patients identified with PNS. This high prevalence has been explained by two primary reasons unrelated to bleeding; poor nutritional status and tumor production of iron-binding proteins such as ferritin and lactoferrin ${ }^{15,16}$. Recent meta-analysis found that anemic patients who required perioperative blood transfusion undergoing radical and partial nephrectomy for localized RCC had 
significantly worse survival outcomes ${ }^{17}$. Another meta-analysis looking at prognostic significance of preoperative anemia in patients undergoing surgery for localized RCC concluded that anemia was associated with earlier recurrence and worse survival after nephrectomy ${ }^{18}$. Similarly, our study showed that anemia was associated with worse survival with significantly higher stage, grade, tumor margin positivity, nodal positivity, age, and higher CCI score. Thus, it is important to recognize RCC as one of the differential diagnosis among patients with intractable anemia in the absence of other clearly causative medical conditions.

The prevalence of other PNS in RCC is estimated at 10-20\% for hypercalcemia, $10-30 \%$ for constitutional symptoms, and $1-8 \%$ for polycythemia ${ }^{1,11}$ [Table 3]. In our cohort, the prevalence of polycythemia was $3.6 \%$ and weight loss was $11.8 \%$ of all the PNS observed, which are in line with findings in the literature. Hypercalcemia was present in only $1.1 \%$ of our cohort with PNS, which is likely due to different thresholds at which hypercalcemia is defined. For example, one study in the US defined hypercalcemia at serum calcium $>10.1 \mathrm{mg} / \mathrm{dL}(2.5$ $\mathrm{mmol} / \mathrm{L})^{14}$, whereas our study in Canadian centres defined hypercalcemia at serum calcium $>2.7$ $\mathrm{mmol} / \mathrm{L}$ to capture more clinically significant hypercalcemia. The lower prevalence of hypercalcemia may also be due to a high proportion of patients $(84 \%)$ from current study who did not have a preoperative calcium level recorded which is often due to one not being drawn as shown in other studies ${ }^{19}$. The implications of PNS from this study should be further evidence for urologists to ensure a full preoperative chemistry panel is obtained. Previous studies have shown that any PNS regardless of subtype is associated with poorer outcomes. Similarly, our analysis of PNS stratified by specific manifestations showed persistent association with unfavorable tumor characteristics and survival outcomes.

To our knowledge, this is one of the largest multi-centered studies evaluating the prognostic impact of PNS on patients with localized RCC undergoing surgery. Several implications can be derived from the findings: first, PNS is strongly predictive of worse patient and tumor characteristics which in turn impacts survival after nephrectomy, and can therefore be useful as a prognostic tool for risk stratification. Secondly, preoperative evaluation of clinical and laboratory PNS should be obtained in all localized RCC patients and third, the presence of PNS may be a marker of higher risk disease that warrants changes in post-operative follow-up protocols and consideration of additional therapeutic measures. More research is needed to elucidate the mechanisms of PNS and optimize the management of patients with this seemingly high-risk manifestation of RCC.

\section{Limitations}

Potential limitations of the study may include missing data, lack of centralized pathology review, lack of data on extended PNS manifestations such as Stauffer's syndrome, lack of differentiation of PNS from signs and symptoms related to other co-morbidities and shorter follow up. In 
addition, this paper only looked at the patients who underwent surgery and it is possible that surgically unfit patients with PNS were excluded.

\section{Conclusions}

In the multi-institutional Canadian cohort of patients undergoing partial or radical nephrectomy for non-metastatic RCC, the presence of PNS is associated with advanced age, higher comorbidity score, and adverse clinical and histological tumor characteristics, which in turn leads to worse oncological outcomes. When accounting for age, comorbidities, and tumor characteristics, PNS is not independently associated with worse survival outcomes, suggesting that it may be a reflection of underlying tumor aggressiveness relative to the patient's resilience. Although not independent prognosticator, presence of PNS should be taken into consideration for timely surgical planning and proper follow up. 


\section{References}

1. Sacco E, Pinto F, Sasso F, et al. Paraneoplastic syndromes in patients with urological malignancies. Urol Int 2009;83(1):1-11. doi:10.1159/000224860

2. Gold PJ, Fefer A, Thompson JA. Paraneoplastic manifestations of renal cell carcinoma. Semin Urol Oncol 1996;14(4):216-222.

3. Kim HL, Belldegrun AS, Freitas DG, et al. Paraneoplastic signs and symptoms of renal cell carcinoma: implications for prognosis. J Urol 2003;170(5):1742-1746. doi:10.1097/01.ju.0000092764.81308.6a

4. Napal Lecumberri S, Pascual Piedrola JI, Solchaga Martinez A, et al. Polycythemia as the first and only manifestation of renal adenocarcinoma. Arch Esp Urol 1992;45(5):476478.

5. Pepper K, Jaowattana U, Starsiak MD, et al. Renal cell carcinoma presenting with paraneoplastic hypercalcemic coma: a case report and review of the literature. J Gen Intern Med 2007;22(7):1042-1046. doi:10.1007/s11606-007-0189-1

6. Jobe BA, Bierman MH, Mezzacappa FJ. Hyperglycemia as a paraneoplastic endocrinopathy in renal cell carcinoma: a case report and review of the literature. Nebr Med J 1993;78(11):349-351.

7. Giannakos G, Papanicolaou X, Trafalis D, et al. Stauffer's syndrome variant associated with renal cell carcinoma. Int J Urol 2005;12(8):757-759. doi:10.1111/j.14422042.2005.01149.x

8. Lee CT, Katz J, Fearn PA, et al. Mode of presentation of renal cell carcinoma provides prognostic information. Urol Oncol 2002;7(4):135-140. doi:10.1016/S1078$1439(01) 00185-5$

9. Luciani LG, Cestari R, Tallarigo C. Incidental renal cell carcinoma-age and stage characterization and clinical implications: study of 1092 patients (1982-1997). Urology 2000;56(1):58-62. doi:10.1016/s0090-4295(00)00534-3

10. Magera JSJ, Leibovich BC, Lohse CM, et al. Association of abnormal preoperative laboratory values with survival after radical nephrectomy for clinically confined clear cell renal cell carcinoma. Urology 2008;71(2):278-282. doi:10.1016/j.urology.2007.08.048

11. Palapattu GS, Kristo B, Rajfer J. Paraneoplastic syndromes in urologic malignancy: the many faces of renal cell carcinoma. Rev Urol 2002;4(4):163-170.

12. Rink M, Kluth LA, Shariat SF, et al. Kaplan-Meier analysis in urological practice. Urologe A 2013;52(6):838-841. doi:10.1007/s00120-013-3150-4

13. Ding GX, Song NH, Feng CC et al. Is there an association between advanced stage of renal cell carcinoma and paraneoplastic syndrome? Med Princ Pract 2010;21:370-374.

14. Moreira DM, Gershman B, Lohse CM, et al. Paraneoplastic syndromes are associated with adverse prognosis among patients with renal cell carcinoma undergoing nephrectomy. World J Urol 2016;34(10):1465-1472. doi:10.1007/s00345-016-1793-7

15. Loughlin KR, Gittes RF, Partridge D, et al. The relationship of lactoferrin to the anemia of renal cell carcinoma. Cancer 1987;59(3):566-571. doi:10.1002/10970142(19870201)59:3<566::aid-cncr2820590335>3.0.co;2-w

16. Kirkali Z, Guzelsoy M, Mungan MU, et al. Serum ferritin as a clinical marker for renal 
cell carcinoma: influence of tumor size and volume. Urol Int 1999;62(1):21-25. doi: $10.1159 / 000030349$

17. Iwata T, Kimura S, Foerster B, et al. Perioperative blood transfusion affects oncologic outcomes after nephrectomy for renal cell carcinoma: A systematic review and metaanalysis. Urol Oncol 2019;37(4):273-281. doi:10.1016/j.urolonc.2019.01.018

18. Xia L, Hu G, Guzzo TJ. Prognostic Significance of Preoperative Anemia in Patients Undergoing Surgery for Renal Cell Carcinoma: A Meta-analysis. Anticancer Res 2017;37(6):3175-3181. doi:10.21873/anticanres.11677

19. Moideen N, Marzouk KH, Matheson KJ, et al. Measuring quality care in localized renal cell cancer: use of appropriate preoperative investigations in a population-based cohort. Curr Oncol 2017 Apr;24(2):e152-e156. doi: 10.3747/co.24.3290. 


\section{Figures and Tables}

Fig. 1. Kaplan-Meier curve estimates of recurrence-free survival, cancer-specific survival, and overall survival. PNS: paraneoplastic syndrome.
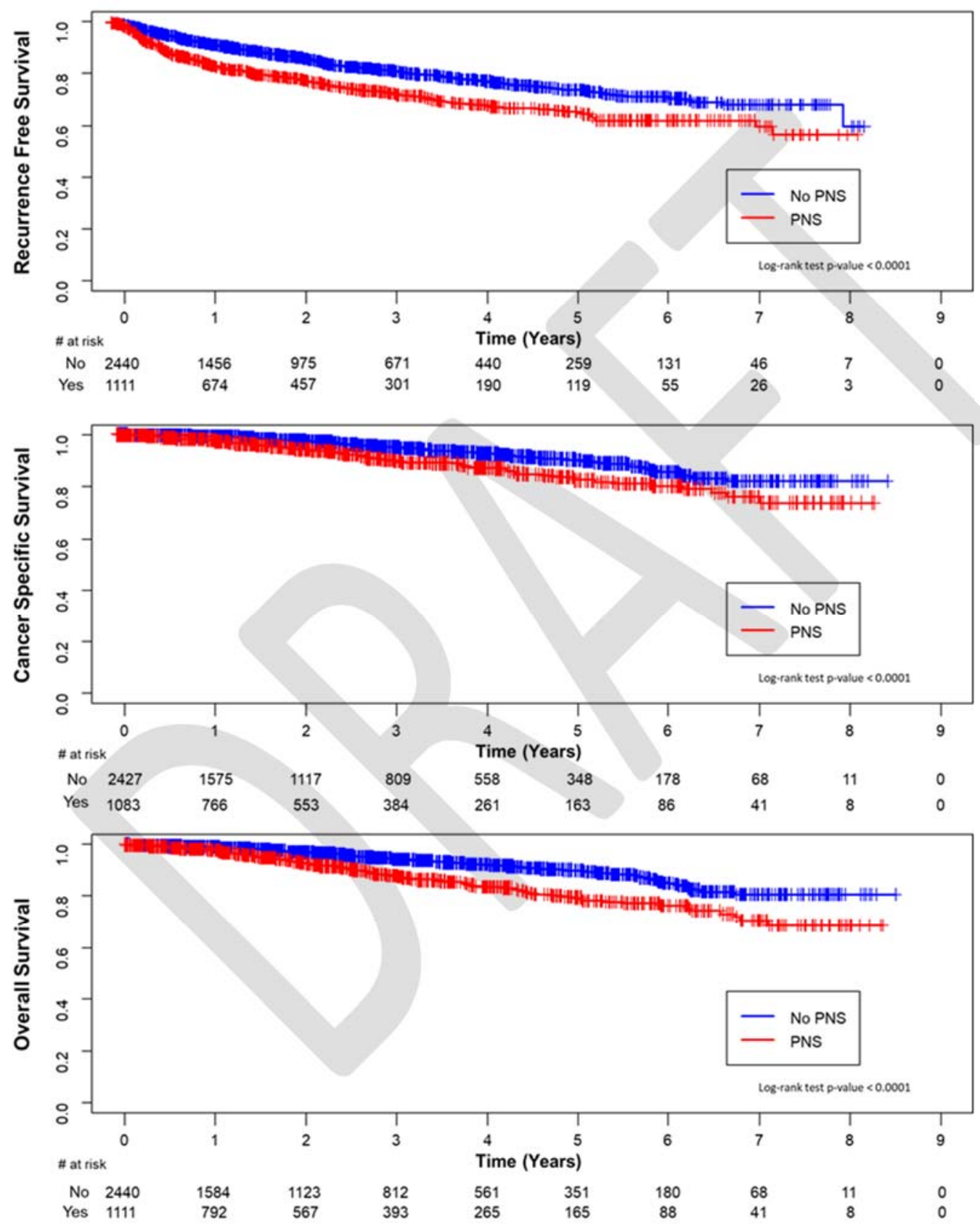


\begin{tabular}{|c|c|c|c|}
\hline & $\begin{array}{c}\text { No } \\
\text { paraneoplastic } \\
\text { syndrome } \\
(\mathbf{n}=\mathbf{3 0 2 3}) \\
\end{array}$ & $\begin{array}{c}\text { Paraneoplastic } \\
\text { syndrome } \\
(n=1314)\end{array}$ & $\mathbf{p}$ \\
\hline Age in years (median [IQR]) & $60.9(52.8,68.7)$ & $63.6(55.3,70.7)$ & $<0.0001$ \\
\hline \multicolumn{4}{|l|}{ Gender } \\
\hline Male & $2033(67.3 \%)$ & $849(64.6 \%)$ & \multirow[t]{2}{*}{0.091} \\
\hline Female & $990(32.7 \%)$ & $465(35.4 \%)$ & \\
\hline \multicolumn{4}{|l|}{ Race $(n=2955)$} \\
\hline White & $1758(85.2 \%)$ & $734(82.4 \%)$ & \multirow{2}{*}{0.055} \\
\hline Non-White & $306(14.8 \%)$ & $157(17.6 \%)$ & \\
\hline Positive family history & $142(4.7 \%)$ & $59(4.5 \%)$ & 0.765 \\
\hline Smoking history $(\mathrm{n}=3871)$ & $1570(57.8 \%)$ & $697(60.2 \%)$ & 0.166 \\
\hline $\begin{array}{l}\text { CCI score (median [IQR]), } \\
(\mathrm{n}=4124)\end{array}$ & $2(1,3)$ & $2(1,3)$ & $<0.0001$ \\
\hline \multicolumn{4}{|l|}{ Clinical stage $(\mathrm{n}=4294)$} \\
\hline T1 & $2244(75.1 \%)$ & $839(64.3 \%)$ & \multirow[t]{3}{*}{$<0.0001$} \\
\hline $\mathrm{T} 2$ & $419(14.0 \%)$ & $235(18.0 \%)$ & \\
\hline $\mathrm{T} 3 / 4$ & $326(10.9 \%)$ & $231(17.7 \%)$ & \\
\hline $\begin{array}{l}\text { Clinical node positivity } \\
(\mathrm{n}=3547)\end{array}$ & $43(1.4 \%)$ & $44(3.3 \%)$ & $<0.0001$ \\
\hline \multicolumn{4}{|l|}{ Pathological grade } \\
\hline G1 & $232(7.7 \%)$ & $75(5.7 \%)$ & \multirow[t]{4}{*}{$<0.0001$} \\
\hline G2 & $1477(48.9 \%)$ & $522(39.7 \%)$ & \\
\hline G3 & $1099(36.3 \%)$ & $512(39.0 \%)$ & \\
\hline G4 & $215(7.1 \%)$ & $205(15.6 \%)$ & \\
\hline \multicolumn{4}{|l|}{ Pathological stage } \\
\hline T1 & $2058(68.1 \%)$ & $758(57.7 \%)$ & \multirow[t]{2}{*}{$<0.0001$} \\
\hline $\mathrm{T} 2$ & $197(6.5 \%)$ & $87(6.6 \%)$ & \\
\hline
\end{tabular}




\begin{tabular}{|l|c|c|c|}
\hline \multicolumn{1}{|c|}{ T3/4 } & $768(25.4 \%)$ & $469(35.7 \%)$ & \\
\hline Margin positivity & $197(6.5 \%)$ & $125(9.5 \%)$ & $<0.0005$ \\
\hline $\begin{array}{l}\text { Pathological node positivity } \\
(\mathrm{n}=4334)\end{array}$ & $38(1.3 \%)$ & $30(2.3 \%)$ & 0.013 \\
\hline Tumor necrosis $(\mathrm{n}=3339)$ & $638(27.2 \%)$ & $383(38.5 \%)$ & $<0.0001$ \\
\hline $\begin{array}{l}\text { Sarcomatoid differentiation } \\
(\mathrm{n}=3322)\end{array}$ & $70(3.0 \%)$ & $70(6.9 \%)$ & $<0.0001$ \\
\hline Histological subtype & & & \\
\hline Clear-cell RCC & $2441(80.7 \%)$ & $1110(84.5 \%)$ & 0.009 \\
\hline Papillary RCC & $84(16.5 \%)$ & $169(12.9 \%)$ & \\
\hline Chromophobe RCC & $84(2.8 \%)$ & $35(2.7 \%)$ & \\
\hline
\end{tabular}

CCI: Charlson comorbidity index; IQR: interquartile range; PNS: paraneoplastic syndrome; RCC: renal cell carcinoma.

\begin{tabular}{|l|c|c|c|c|c|c|c|c|c|}
\hline \multicolumn{7}{|l|}{ Table 2. Univariable and multivariable analysis on survival outcomes } \\
\hline \multicolumn{2}{|l|}{} & \multicolumn{7}{|c|}{ Univariable analysis } & \multicolumn{3}{c|}{ Multivariable analysis } \\
\hline Parameter & & HR & \multicolumn{2}{c|}{$\mathbf{9 5 \%}$ CI } & p & HR & \multicolumn{2}{|c|}{$\mathbf{9 5 \%}$ CI } & p \\
\hline Paraneoplastic & & & & & & & & & \\
syndrome & RFS & 1.67 & 1.48 & 1.90 & $<0.0001$ & 1.13 & 0.98 & 1.31 & 0.079 \\
Yes vs. no & CSS & 1.85 & 1.34 & 2.54 & 0.0002 & 1.29 & 0.96 & 1.74 & 0.096 \\
& OS & 1.04 & 0.78 & 1.39 & 0.789 & 1.22 & 0.96 & 1.55 & 0.10 \\
\hline Age at & & & & & & & & & \\
nephrectomy & OS & 1.05 & 1.04 & 1.06 & $<0.0001$ & 1.04 & 1.03 & 1.06 & $<0.0001$ \\
Increase by 1 & & & & & & & & & \\
year & & & & & & & & & \\
& & & & & & & & & \\
\hline CCI score & & & & & & & & & \\
Increase by 1 & OS & 1.42 & 1.32 & 1.4 & $<0.0001$ & 1.40 & 1.28 & 1.53 & $<0.0001$ \\
unit & & & & & & & & & \\
\hline Fuhrman grade & & & & & & & & & \\
G1 vs. G4 & RFS & 0.05 & 0.03 & 0.09 & $<0.0001$ & 0.20 & 0.13 & 0.31 & $<0.0001$ \\
& CSS & 0.01 & 0.003 & 0.08 & $<0.0001$ & 0.05 & 0.01 & 0.21 & $<0.0001$ \\
& OS & 0.05 & 0.02 & 0.11 & $<0.0001$ & 0.16 & 0.06 & 0.42 & 0.0002 \\
G2 vs. G4 & RFS & 0.11 & 0.08 & 0.15 & $<0.0001$ & 0.33 & 0.26 & 0.41 & $<0.0001$ \\
& CSS & 0.11 & 0.07 & 0.18 & $<0.0001$ & 0.26 & 0.18 & 0.38 & $<0.0001$ \\
& OS & 0.12 & 0.08 & 0.18 & $<0.0001$ & 0.25 & 0.17 & 0.36 & $<0.0001$ \\
G3 vs. G4 & RFS & 0.29 & 0.21 & 0.38 & $<0.0001$ & 0.52 & 0.39 & 0.68 & $<0.0001$ \\
\hline
\end{tabular}




\begin{tabular}{|l|c|c|c|c|c|c|c|c|c|} 
& CSS & 0.28 & 0.18 & 0.40 & $<0.0001$ & 0.41 & 0.29 & 0.58 & $<0.0001$ \\
& OS & 0.28 & 0.19 & 0.42 & $<0.0001$ & 0.39 & 0.28 & 0.54 & $<0.0001$ \\
\hline Tumor margin & & & & & & & & & \\
Positive vs. & RFS & 2.14 & 1.68 & 2.72 & $<0.0001$ & 1.45 & 1.13 & 1.85 & 0.003 \\
negative & CSS & 2.44 & 1.53 & 3.87 & 0.0002 & 1.49 & 0.95 & 2.34 & 0.08 \\
& OS & 2.46 & 1.63 & 3.71 & $<0.0001$ & 1.54 & 0.98 & 2.43 & 0.062 \\
\hline Tumor size & & & & & & & & & \\
Increase by 1 & RFS & 1.22 & 1.18 & 1.25 & $<0.0001$ & 1.12 & 1.09 & 1.14 & $<0.0001$ \\
cm & CSS & 1.18 & 1.13 & 1.24 & $<0.0001$ & 1.08 & 1.03 & 1.13 & 0.001 \\
& OS & 1.17 & 1.13 & 1.22 & $<0.0001$ & 1.10 & 1.06 & 1.15 & $<0.0001$ \\
\hline Pathological & & & & & & & & & \\
stage & RFS & 0.12 & 0.10 & 0.14 & $<0.0001$ & 0.30 & 0.24 & 0.37 & $<0.0001$ \\
T1 vs. T3/T4 & CSS & 0.15 & 0.10 & 0.23 & $<0.0001$ & 0.37 & 0.26 & 0.52 & $<0.0001$ \\
& OS & 0.18 & 0.14 & 0.24 & $<0.0001$ & 0.56 & 0.41 & 0.76 & 0.0002 \\
\multicolumn{1}{|c|}{ T2 vs. T3/T4 } & RFS & 0.50 & 0.40 & 0.61 & $<0.0001$ & 0.56 & 0.43 & 0.73 & $<0.0001$ \\
& CSS & 0.44 & 0.29 & 0.66 & $<0.0001$ & 0.54 & 0.36 & 0.82 & 0.004 \\
& OS & 0.51 & 0.34 & 0.76 & 0.001 & 0.72 & 0.46 & 1.14 & 0.16 \\
\hline Histological & & & & & & & & & \\
subtype & RFS & 0.47 & 0.29 & 0.75 & 0.002 & 0.45 & 0.29 & 0.68 & 0.0002 \\
Chromophobe & CSS & 0.31 & 0.16 & 0.60 & 0.0004 & 0.40 & 0.21 & 0.75 & 0.004 \\
vs. clear-cell & OS & 2.09 & 1.60 & 2.74 & $<0.0001$ & 0.45 & 0.23 & 0.86 & 0.015 \\
& & & & & & & & & \\
Papillary vs. & RFS & 0.62 & 0.48 & 0.81 & 0.0004 & 0.96 & 0.75 & 1.25 & 0.78 \\
clear-cell & CSS & 1.07 & 0.78 & 1.69 & 0.69 & 1.87 & 1.35 & 2.61 & 0.0002 \\
& OS & 0.34 & 0.20 & 0.59 & 0.0001 & 1.52 & 1.15 & 2.03 & 0.004 \\
\hline
\end{tabular}

CCI: Charlson comorbidity index; CI: confidence interval; CSS: cancer specific survival; HR: hazard ratio; OS: overall survival; RFS: recurrence-free survival. 


\begin{tabular}{|c|c|c|c|c|}
\hline Author & Year & Subjects & $\begin{array}{l}\text { PNS studied and } \\
\text { prevalence }(\%)\end{array}$ & Findings \\
\hline Kim et $\mathrm{al}^{3}$ & 2003 & $\begin{array}{l}\mathrm{n}=1046 \text { patients } \\
\text { undergoing } \\
\text { nephrectomy for } \\
\text { RCC }\end{array}$ & $\begin{array}{c}\text { Anemia }(52 \%) ; \\
\text { cachexia }(35 \%) ; \\
\text { hepatic dysfunction } \\
(32 \%) \text {; weight loss } \\
(23 \%) \text {; malaise }(19 \%) ; \\
\text { hypercalcemia }(13 \%) ; \\
\text { anorexia }(11 \%) \text {; fever } \\
(7.8 \%), \text { hypertension } \\
(2.5 \%)\end{array}$ & $\begin{array}{l}\text { Cachexia, weight loss, } \\
\text { anorexia, and malaise, } \\
\text { predicts worse disease- } \\
\text { specific survival }\end{array}$ \\
\hline $\begin{array}{l}\text { Magera et } \\
\mathrm{al}^{10}\end{array}$ & 2008 & $\begin{array}{l}\mathrm{n}=1707 \text { patients } \\
\text { undergoing } \\
\text { radical } \\
\text { nephrectomy for } \\
\text { localized clear- } \\
\text { cell RCC }\end{array}$ & $\begin{array}{l}\text { Elevated ALP }(81 \%) ; \\
\text { elevated ESR }(44 \%) ; \\
\text { anemia }(35 \%) ; \\
\text { hypercalcemia }(9 \%)\end{array}$ & $\begin{array}{l}\text { Anemia, hypercalcemia, } \\
\text { elevated ESR are } \\
\text { independently associated } \\
\text { with worse cancer- } \\
\text { specific survival }\end{array}$ \\
\hline $\begin{array}{l}\text { Ding et } \\
\mathrm{al}^{13}\end{array}$ & 2012 & $\begin{array}{l}\mathrm{n}=1512 \text { patients } \\
\text { undergoing } \\
\text { nephrectomy for } \\
\text { RCC }\end{array}$ & $\begin{array}{c}\text { Any PNS }(68 \%) ; \\
\text { elevated ESR }(36 \%) ; \\
\text { hypertension }(25 \%) ; \\
\text { cachexia }(23 \%) ; \\
\text { anemia }(21 \%) ; \text { pyrexia } \\
(16 \%) \text {; liver } \\
\text { dysfunction }(9.7 \%) ; \\
\text { hypercalcemia }(4.6 \%) ; \\
\text { polycythemia: }(4.1 \%) ; \\
\text { varicocele }(1.9 \%) ; \\
\text { neuromyopathy }(0.7 \%)\end{array}$ & $\begin{array}{l}\text { Pyrexia, elevated ESR, } \\
\text { cachexia and varicocele } \\
\text { were associated with } \\
\text { advanced clinical and } \\
\text { pathological stage }\end{array}$ \\
\hline $\begin{array}{l}\text { Moreira et } \\
\mathrm{al}^{14}\end{array}$ & 2016 & $\begin{array}{l}\mathrm{n}=2865 \text { patients } \\
\text { undergoing } \\
\text { nephrectomy for } \\
\text { localized RCC }\end{array}$ & $\begin{array}{c}\text { Any PNS (22\%); } \\
\text { anemia }(23 \%) ; \text { liver } \\
\text { dysfunction }(10 \%) ; \\
\text { hypercalcemia }(9 \%) ; \\
\text { hypertension }(2 \%) ; \\
\text { polycythemia }(1 \%)\end{array}$ & $\begin{array}{l}\text { Presence of any PNS was } \\
\text { associated with worse } \\
\text { tumor characteristics } \\
\text { (larger size, higher stage, } \\
\text { higher grade) and cancer- } \\
\text { specific survival. On } \\
\text { multivariate analysis, } \\
\text { PNS did not remain } \\
\text { associated with worse } \\
\text { survival } \\
\end{array}$ \\
\hline $\begin{array}{l}\text { Sun et al } \\
\text { [current } \\
\text { study] }\end{array}$ & 2020 & $\begin{array}{c}\mathrm{n}=4337 \text { patients } \\
\text { from CKCis } \\
\text { database }\end{array}$ & $\begin{array}{l}\text { Any PNS }(30.3 \%) ; \\
\text { anemia }(90 \% \text { of all } \\
\text { PNS); weight loss }\end{array}$ & $\begin{array}{l}\text { PNS associated with } \\
\text { older age, higher } \\
\text { comorbidity score, }\end{array}$ \\
\hline
\end{tabular}




\begin{tabular}{|c|c|c|c|}
\hline & $\begin{array}{c}\text { undergoing } \\
\text { radical or partial } \\
\text { nephrectomy for } \\
\text { localized RCC }\end{array}$ & $\begin{array}{c}\text { (11.8\% of all PNS); } \\
\text { polycythemia }(3.6 \% \text { of } \\
\text { all PNS); }\end{array}$ & $\begin{array}{c}\text { advanced tumor stage } \\
\text { and aggressive tumor } \\
\text { histology. On } \\
\text { hyltivariable analysis, } \\
\text { baseline PNS not } \\
\text { all PNS) }\end{array}$ \\
$\begin{array}{c}\text { independently associated } \\
\text { with recurrence or death }\end{array}$ \\
\hline
\end{tabular}

ALP: alkaline phosphatase; CKCis: Canadian Kidney Cancer information system; ESR: erythrocyte sedimentation rate; PNS: paraneoplastic syndromes; RCC: renal cell carcinoma. 